\title{
Characteristics of Humidity-Temperature Changing in the Below-Grade Concrete Structure by Applying Waterproofing Materials on the Exterior Wall
}

\author{
Sang-Mook Chang, ${ }^{1}$ Sang-Keun Oh, ${ }^{2}$ Deok-Suk Seo, ${ }^{3}$ and Sung-Min Choi ${ }^{4}$ \\ ${ }^{1}$ Department of Building Equipment Plant, Yuhan University, 590 Kyunin-ro, Sosa-gu, Bucheon, \\ Gyeonggi-do 422-749, Republic of Korea \\ ${ }^{2}$ Architectural Engineering, Seoul National University of Science and Technology, 232 Gongneung-ro, Nowon-gu, \\ Seoul 139-743, Republic of Korea \\ ${ }^{3}$ Architectural Engineering, Halla University, 28 Hallauniv-Road, Wonju-si, Gangwon-do 220-712, Republic of Korea \\ ${ }^{4}$ Research Institute of Construction Technology, Seoul National University of Science and Technology, 232 Gongneung-ro, \\ Nowon-gu, Seoul 139-743, Republic of Korea \\ Correspondence should be addressed to Sung-Min Choi; housedoctor@seoultech.ac.kr
}

Received 29 April 2015; Accepted 8 July 2015

Academic Editor: João M. P. Q. Delgado

Copyright (c) 2015 Sang-Mook Chang et al. This is an open access article distributed under the Creative Commons Attribution License, which permits unrestricted use, distribution, and reproduction in any medium, provided the original work is properly cited.

\begin{abstract}
The water leakage in an underground space cannot easily be repaired owing to the characteristics of the underground space, which not only causes continuous inconvenience to the apartment residents but also facilitates condensation. Thus, the effects of different waterproofing methods in underground spaces on changes in temperature and humidity should be quantitatively studied to establish strong measures for the condensation issue. In this study, two types of specimens were produced separately by dividing the waterproofing materials applied to underground structures into exterior and interior waterproofing construction methods; thereafter, changes in the temperature and humidity inside the specimens were observed. The test results of the evaluation regarding condensation in underground structures indicated that when exterior waterproofing materials are applied, thermal insulation maintains a steady interior temperature and keeps the humidity at an appropriate level, thereby preventing the creation of an environment conducive to the occurrence of condensation.
\end{abstract}

\section{Introduction}

Waterproofing technology to prevent water leakage underneath apartments is regarded as an important safety technology for construction quality that prevents safety-related accidents and protects national infrastructure and facilities [1]. However, because waterproofing work is carried out by humans, the implementation often lacks precision [2]. In addition, in many cases, humidity in concrete surfaces is constantly present in underground spaces [3], so it is generally accepted that complete waterproofing cannot be practically achieved in underground structures [4]. Accordingly, although water leakage is permitted in most recently constructed apartments, interior waterproofing is applied by using cement-based waterproof material such as polymermodified waterproof mortar [5] to allow induced drainage.

However, a type of interior waterproofing material that allows leakage in the underground spaces of apartments may hinder the long-term safety of the underground structures, reduce the service life, or damage interior materials as a result of dew condensation [6], which have become major sources of deterioration to residents' living environments.

Normally, because the accountability of such defects due to leakage or condensation [7] is not clearly assigned, the Korea Consumer Agency received many complaints concerning leakage and condensation problems not only 


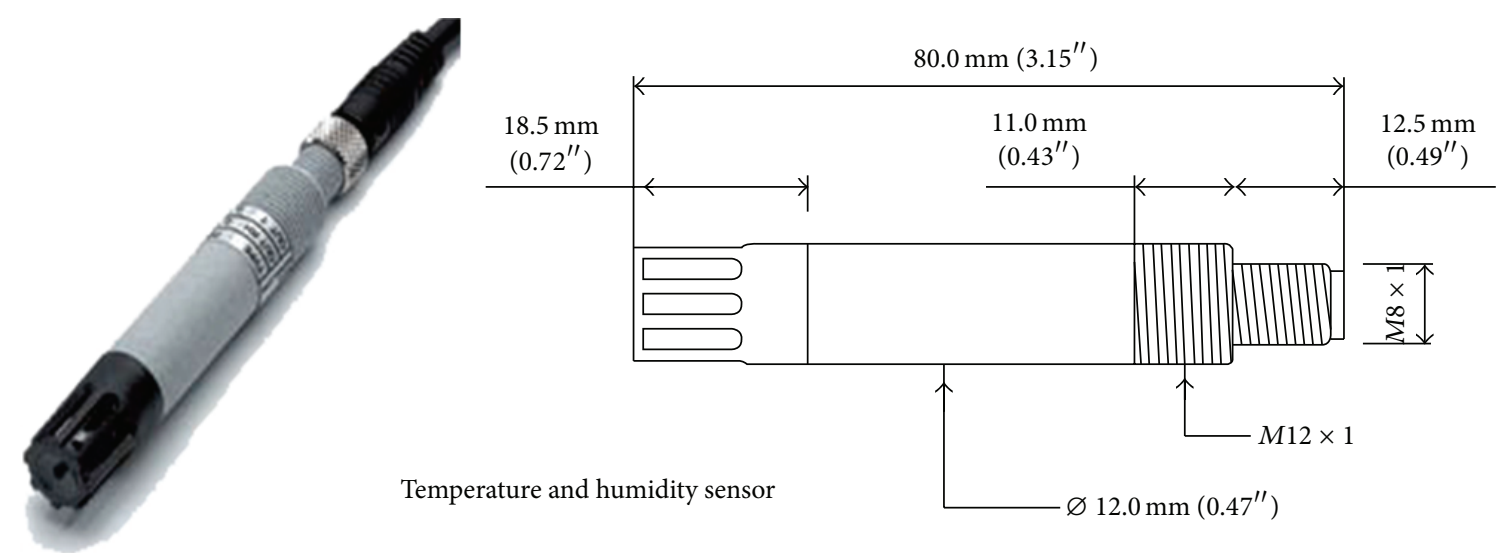

FIgURE 1: Schematic diagram of installation of the sensor.

in the interior houses but also in common areas such as underground parking lots; these represent serious concerns [8].

In recent years, most underground parking lots in apartments have been designed to directly access the residential area [9], and interior waterproofing (induced drainage) has been applied to most underground parking structures except for the top floor, which is susceptible to leakage at all times [10]. Such leakage causes inconvenience to the residents and easily introduces dew condensation $[11,12]$.

Thus, a fundamental proofing measure (exterior waterproofing) should be established as a priority at the design construction phase to minimize disputes due to leakage and condensation [13]. It is true that leakage prevention effects are predictable owing to the application of exterior waterproofing [14]. But few studies have examined the correlations of condensation conditions (changes in conditions of temperature and humidity) in underground spaces, and no concrete, validated data are available [15]. Thus, an objective basis should be provided regarding the effect of waterproofing construction methods (exterior and interior waterproofing) on condensation environments in underground parking lots of apartments; and this basis should be actively utilized in the waterproofing design and material selection phases for underground structures [16].

In this study, the effects of the application of exterior waterproofing are verified as a measure to reduce condensation inside concrete structures constructed in maintenance, through experiments into the characteristics of changes in temperature and humidity according to seasonal conditions. These experiments separately examined the application methods (interior waterproofing or exterior waterproofing) of waterproofing layers applied to the outer walls in underground parking lots of apartments.

\section{Research Scope and Methodology}

2.1. Research Scope. In this study, condensation occurring in the winter season was first examined as a primary objective by evaluating the importance of test period and test loads, while conducting secondary experiments in the winter, spring/autumn, and summer seasons. For getting the results are based on sufficient findings regarding the test results under the conditions of three seasons.

2.2. Study Method. An immersion test was conducted by using concrete box-type specimens, assuming the environmental conditions of an underground concrete structure in which underground water exists; the changes in temperature and humidity were observed according to the different conditions of specimen composition. The test was intensively conducted under the conditions of three seasons: winter, spring/autumn, and summer. Two test periods, 7 and 14 days, were used separately to identify the difference between heat and cool conditions in the winter season, followed by a test under spring/autumn conditions for seven days.

\section{Configuration of the Specimens and Test Method}

3.1. Temperature and Humidity Sensors. To measure temperature and humidity inside and outside the specimen, a multichannel data logger (model Agilent 34972A) was employed, and temperature and humidity sensors were installed at the location of each specimen to simultaneously record data, as shown in Figure 1. In addition, sensors were installed to observe changes in the external temperature of the concrete exposed to the atmosphere, as well as the wall side of the concrete box, which was immersed in water, replicating the existence of external underground water (refer to the specifications in Figure 2 and Table 1).

The interval for the measurements recorded by the data logger was set to $1 \mathrm{~min}$ and the conditions of the specimens were periodically checked during the test period to observe the presence of condensation. In addition, the presence of heat transfer fluid, maintaining the height of the water immersing the concrete box, and the record of the data logger were constantly inspected.

3.2. Concrete Box-Type Specimens. In this study, two types of specimens were produced separately by dividing the application types of waterproofing layers applied to underground structures into exterior and interior waterproofing construction methods. Furthermore, depending on the strength of the 
TABLE 1: Specifications of the temperature and humidity sensor.

\begin{tabular}{lcc}
\hline & Category & Specification \\
\hline & Measurement range (relative humidity) & Relative humidity (RH) $0-100 \%$ \\
& Measurement range (temp.) $0-100^{\circ} \mathrm{C},-20-80^{\circ} \mathrm{C}$ & $< \pm 2 \% \mathrm{RH}(10-99 \% \mathrm{RH})$ \\
Temperature and humidity sensor & Accuracy at $23^{\circ} \mathrm{C}$ & $< \pm 1 \% \mathrm{RH}$ \\
& Annual stability of relative humidity & $<10$ s normally (up to $90 \%)$ \\
& Relative humidity response time & $0-1$ VDC, $0-5 \mathrm{VDC}, 0-10 \mathrm{VDC}$ \\
\hline Data logger (Agilent 34972A) & Selected signal output & 14-35 VDC, $4.5-35 \mathrm{VDC}, 14-26 \mathrm{VDC}$ \\
& Supply voltage & Length: $80 \mathrm{~mm}, \mathbb{C} 12 \mathrm{~mm}$ \\
\hline
\end{tabular}



$\bigcirc$ Humidity $(H)$ sensor 1

Temperature $(T)$ sensor 1

FIGURE 2: Schematic diagram of the specimens.

base concrete in the underground structures, condensation may occur differently, so 12 specimens of high-strength concrete (HSC) and ordinary Portland cement (OPC) were manufactured, as listed in Table 2.

The specimen was a concrete square box. The top of the box was covered by a square lid $600 \mathrm{~mm}$ in length and width, which was made from acrylic and sealed. The center area of the lid was designed to allow the installation of heat transfer fluid that can facilitate heating, as well as temperature and humidity sensors that can measure the temperature and humidity of the interior of the box, as shown in Figure 2. The specimens were immersed in water to approximately $300 \mathrm{~mm}$ in depth, assuming the conditions of the underground water level on the exterior of the underground space.

After the 28-day curing process was completed after concrete placement, the manufactured exterior waterproofing specimens were coated with urethane-coated waterproof material as thickness of $3 \mathrm{~mm}$ [4], whereas the interior waterproofing specimens were coated with cement-mixed polyester-based waterproof material as thickness of $1 \mathrm{~mm}$ [17]. After coating with the waterproof material, another 14day curing process was completed and the final specimens were produced as the top cover was installed on top of the concrete box, along with temperature and humidity sensors and heat transfer fluid (incandescent lamps, $30 \mathrm{~W}$ ). After the heat transfer fluid and temperature/humidity sensors were completely installed, the two separated half covers were completely bonded and sealed with silicone at the intersection. The intersection with the concrete box was also attached and sealed with silicone. The mixing condition of concrete specimen is fixed slump of $13 \mathrm{~cm}$, water-cement ratio of $40 \%$, and S/A of $42 \%$. The strength of concrete specimen is tested by KS F 2403 at 28 days. Additionally, it is checked by rebound hardness method using Schmidt hammer. The test result of the concrete compressive strengths and the condition of specimens are as in Tables 3 and 4.

\section{Test Results and Discussion}

4.1. Basic Performance Evaluation of the Applied Materials. The basic performance evaluation was a related KS (Korean Standards) performance evaluation on waterproof materials applied to the specimens (exterior waterproofing of urethane-coated waterproof material, interior waterproofing of cement-mixed polymer-modified waterproof material), which aimed to identify basic performance of the waterproof materials coated on the specimens before conducting the condensation test. The test was conducted according to the test specifications. The urethane-coated waterproof materials are specified in KS F 3211 [18], and the test items for the cement-mixed polymer-modified waterproof material are specified in KS F 4919 [19], as listed in Table 2. The test result verified that the criteria for all test items were satisfied.

To verify the strength of the manufactured concrete specimens, the compressive strength test results are as in Table 4 .

\subsection{Concrete Box-Type Specimens}

\subsubsection{Test Results of the Winter Season Specimens}

(1) Temperature of the Interior of the Specimen in Winter. The test was conducted from February 12 to 25, 2013, for 14 days. To compare the results from heated and unheated conditions, 
TABle 2: Details about mortar specimens by temperature.

\begin{tabular}{|c|c|c|c|}
\hline \multirow[b]{2}{*}{ Category } & \multicolumn{2}{|c|}{ Type of specimen } & \multirow[b]{2}{*}{ Uncoated (N) } \\
\hline & $\begin{array}{l}\text { Exterior waterproofing } \\
{ }^{*} 1(\mathrm{O})\end{array}$ & $\begin{array}{l}\text { Interior waterproofing } \\
{ }^{*} 2(\mathrm{I})\end{array}$ & \\
\hline \multicolumn{4}{|c|}{ Concrete box } \\
\hline HSC & HSC-O & HSC-I & HSC-N \\
\hline $\mathrm{OPC}$ & OPC-O & OPC-I & OPC-N \\
\hline
\end{tabular}

*1: urethane coated waterproof material (thickness $2 \mathrm{~mm}$ ).

*2: cement-mixed polymer-modified waterproof material (thickness $1 \mathrm{~mm}$ ).

TABLE 3: Details about concrete specimen by mixing ratio.

\begin{tabular}{|c|c|c|c|c|c|c|c|}
\hline \multirow[b]{2}{*}{ Division } & \multirow[b]{2}{*}{$\begin{array}{l}\text { Maximum size of } \\
\text { coarse aggregate }(\mathrm{mm})\end{array}$} & \multicolumn{3}{|c|}{ Unit volume of concrete } & \multirow[b]{2}{*}{$\mathrm{W} / \mathrm{C}(\%)$} & \multirow[b]{2}{*}{ S/A (\%) } & \multirow[b]{2}{*}{ Slump $(\mathrm{cm})$} \\
\hline & & Cement $\left(\mathrm{kg} / \mathrm{m}^{3}\right)$ & $\begin{array}{c}\text { Fine } \\
\text { aggregate } \\
\left(\mathrm{kg} / \mathrm{m}^{3}\right)\end{array}$ & $\begin{array}{c}\text { Coarse } \\
\text { aggregate } \\
\left(\mathrm{kg} / \mathrm{m}^{3}\right)\end{array}$ & & & \\
\hline HSC & 25 & 378 & 733 & 999 & 40 & 42 & 13 \\
\hline OPC & 25 & 378 & 733 & 999 & 50 & 42 & 13 \\
\hline
\end{tabular}

TABLE 4: Compressive strength of the concrete specimen.

\begin{tabular}{lcc}
\hline Division & Result & Test method \\
\hline Compressive strength test & & \\
HPC & $29.34 \mathrm{MPa}$ & KS F 2403 \\
OPC & $17.82 \mathrm{MPa}$ & \\
Rebound hardness test & & \\
HPC & $27.44 \mathrm{MPa}$ & Schmidt hammer test \\
OPC & $18.29 \mathrm{MPa}$ & \\
\hline
\end{tabular}

the interior heating in the winter season was assumed while the heat transfer fluid (light bulbs) inside the box was turned on and then turned off after eight days. The test results are shown in Figure 3.

The test results showed that the exterior temperature was measured at approximately $9-16^{\circ} \mathrm{C}$, whereas the interior temperature was measured at approximately $17-20^{\circ} \mathrm{C}$. The exterior temperature varied in the range of $4-5^{\circ} \mathrm{C}$, according to the daily temperature change, whereas the interior temperature varied in a smaller range of $1-2^{\circ} \mathrm{C}$. This result was revealed because the influence of the external temperature was limited owing to the operation of the inner heat transfer fluid (light bulbs) and the immersion of tightly closed specimens in water. However, after the heat transfer fluid stopped its operation, synchronization with the exterior temperature was observed more clearly, particularly at the low temperature.

The test results indicated that the overall temperature in the interior of the box changed with the same trend as the change in the exterior temperature for all six specimens, although the variance was not excessive. For three days after the test start, the temperature increased rapidly from approximately $11^{\circ} \mathrm{C}$ up to approximately $20^{\circ} \mathrm{C}$; thereafter, the temperature variance was maintained at approximately $2^{\circ} \mathrm{C}$, according to the exterior temperature change. This was attributable to the incandescent lamps used as heat

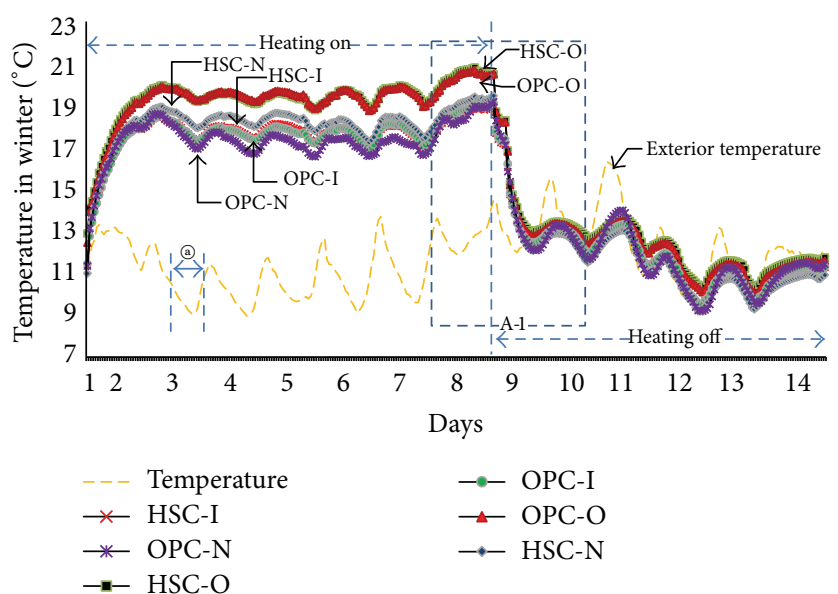

FIgURE 3: Result of the measurement of temperature of the interior of the specimen in winter.

transfer fluid, causing the interior temperature to increase overall. The temperature between specimens was distinctively differentiated between three-day and four-day durations; this temperature difference was maintained constantly until the heating was turned off.

As shown in Figure 4, the specimens maintaining the highest temperature were the high-strength specimen (HSC$\mathrm{O})$ and ordinary strength specimen (OPC-O). Exterior waterproofing was applied to both specimens, which showed nearly similar temperature changes. The specimens maintaining the next highest temperatures were the high-strength uncoated specimen (HSC-N), followed by high-strength specimen (HSC-I) and ordinary strength specimen (OPC-I). Interior waterproofing was applied to each specimen, which showed similar temperature distribution. The specimen that maintained the lowest temperature was the uncoated specimen of ordinary strength concrete without waterproofing (OPC-N). 


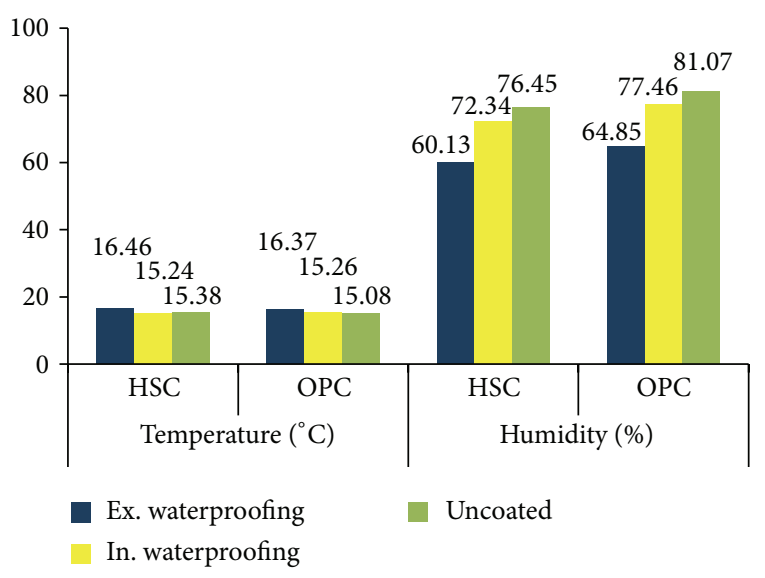

Figure 4: Measurement results of the mean temperature and average humidity of the specimens under winter conditions.

It was verified that the specimens to which the exterior waterproofing was applied (HSC-O, OPC-O) maintained a higher temperature of approximately $1.13^{\circ} \mathrm{C}$, on average, than the specimens to which interior waterproofing was applied (HSC-I, OPC-I) and uncoated specimens (HSC-N, OPC-N). In addition, the specimens to which interior waterproofing was applied displayed a temperature range $\left(15.08-15.37^{\circ} \mathrm{C}\right.$, on average) similar to the uncoated specimens, showing no significant difference.

The specimens to which exterior waterproofing was applied were less sensitive to exterior temperature changes and higher insulation properties that maintained interior temperatures than the uncoated specimens and the specimens to which interior waterproofing was applied. No significant insulation performance difference was found between the interior waterproofing specimen and the uncoated specimens. This result proves that moisture was blocked from the exterior owing to the exterior waterproofing layer, which prevented the low temperature of the outside from penetrating to the interior, resulting in improved insulation performance as a result of the water blocked by the exterior waterproofing.

The OPC-N specimens displayed a different temperature decrease trend after the cessation of heat transfer fluid compared to other specimens, which showed similar temperature decrease trends, as shown in Figure 5 (" $\mathrm{A}$ " indicates a temperature decrease zone). In addition, the uncoated specimens of ordinary strength experienced rapid temperature increases steeply ahead of some other specimens in the " $B$ " temperature change zone, which experienced temperature decreases until reaching the exterior temperature and gradual temperature increases following increases in the exterior temperature.

Based on this result, it can be concluded that uncoated specimens of ordinary strength were more sensitive to changes in exterior temperature, which reduces the insulation performance further than other specimens. Although differences in the insulation performance are not extensive between specimens to which interior waterproofing is applied and uncoated specimens, uncoated specimens are more sensitive to changes in the exterior temperature, thereby increasing condensation. In addition, given that uncoated

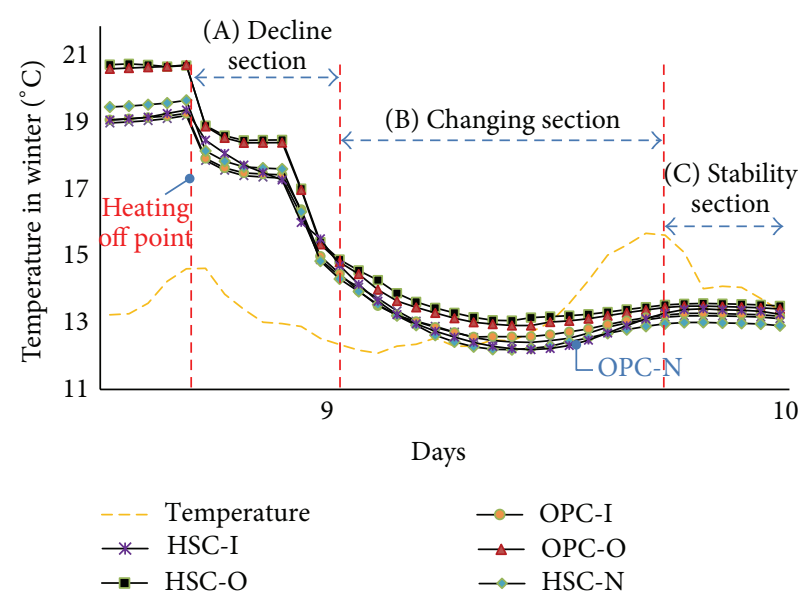

FIGURE 5: Temperature change zone (A-1) after heating was turned off.

ordinary strength concrete specimens were more sensitive to changes in exterior temperature than uncoated high-strength concrete specimens, the strength of the structures may be an influencing factor in the occurrence of condensation, which is attributable to the difference between impermeability and internal texture caused by the difference in density.

On the third day since the beginning of the test ("a)" zone in Figure 3), condensation (frost) was generated on all interior waterproofing and uncoated specimens in the transparent acrylic plate that covered the concrete box. This condensation continued for approximately $12 \mathrm{~h}$, except for two specimens to which exterior waterproofing was applied.

In summary, the test result showed that high-strength concrete structures are less sensitive to exterior temperatures than ordinary strength concrete structures and that applying waterproofing layers makes structures less susceptible to exterior temperature changes than not applying waterproofing. In addition, the application of exterior waterproofing is the most effective way to improve the performance of insulation performance and the prevention of condensation compared to the application of interior waterproofing.

(2) Humidity of the Interior of the Specimen in Winter. The test measuring the humidity of the interior of the specimens was conducted for 14 days (two weeks), as with the temperature measurement. The test first assumed that interior heating was provided by operating the heat transfer fluid (light bulbs); next, the heat transfer fluid was stopped after eight days to examine the condition of no interior heating and the results were compared. The test results are shown in Figure 6.

The test results indicated that the humidity of all six specimens in the interior of the boxes changed with a similar trend, according to the trend of changes in exterior humidity. The rank of the humidity at the beginning of the test was maintained without changes until the test was completed. The outdoor humidity exhibited large variance within the range of $30 \%-50 \%$, according to the daily changes, whereas the interior humidity of the specimens was maintained with few changes after the initial increase (on the first day). These results were obtained because the concrete specimens were 


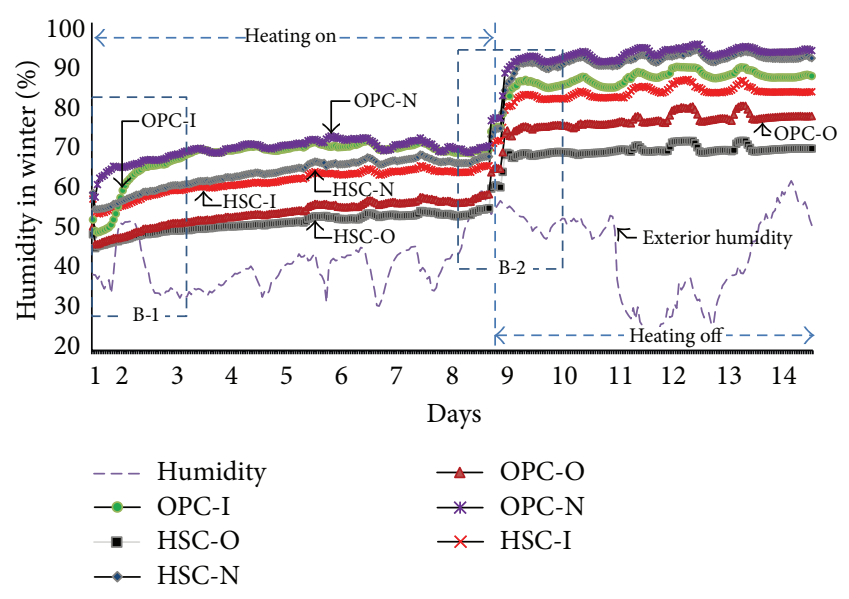

FIGURE 6: Results of humidity measurements of the interior of the specimens in winter.

completely sealed and immersed in water; thus, they were barely affected by the exterior temperature and humidity. It was also found that the humidity increased rapidly and difference in humidity between specimens was clear after the heat transfer fluid was not operated. Based on this result, the interior humidity can be controlled by operating the heat transfer fluid. This control would be more obvious if it was combined with the application of exterior waterproofing.

As shown in Figure 4, the specimen that maintained the lowest humidity was HSC-O, as with the temperature measurement. The specimen that maintained the highest humidity was OPC-N.

The OPC-O specimens maintained low humidity, similar to HSC-O. Both of the specimens with exterior waterproof applied (HSC-O, OPC-O) maintained lower humidity by approximately $7.5 \%-20.9 \%(14.34 \%$, on average) than those specimens with interior waterproofing applied (HSC-I, OPCI) and the uncoated specimens (HSC-N, OPC-N).

Therefore, the specimens with exterior waterproofing applied were less sensitive to changes in the exterior humidity, thereby maintaining lower humidity and condensation than the uncoated specimens and those with interior waterproofing applied.

These humidity test results were slightly different from the temperature test results because no significant difference was found between the interior temperature of the box with interior waterproofing and no coating specimens. However, the difference in humidity between the specimens with interior waterproofing applied and no coating was approximately $4 \%$, on average. In addition, high and ordinary strength specimens showed a difference in humidity of approximately $5 \%$, which is different from the test results for temperature. These differences were generated because the interior waterproofing layer (cement-mixed polymer-modified waterproof material) had zero or minimal effect of blocking the exterior temperature, whereas it had some effect of blocking exterior moisture.

However, a cement-based waterproofing layer only delays the movement of moisture by increasing the permeability coefficient as a result of the watertight texture; thus, it cannot form a waterproofing membrane (or a humidityblocking membrane) that is as complete as the membrane in waterproofing layers.

The initial conditions of the interior humidity of the specimens in the test indicated the highest humidity in ordinary strength uncoated specimens, which displayed the rapid increase in humidity from the humidity change point, in contrast with other specimens, as shown in Figure 7.

In addition, in contrast with other specimens, OPC-I exhibited a rapid increase in humidity from the "(b)" point in Figure 7, after the humidity was maintained for a period. This result occurred because the interior waterproofing specimen of ordinary strength reacted more sensitively to the exterior humidity than other specimens as the exterior humidity started to increase from the "(b)" point.

In addition, because the internal texture of ordinary strength concretes is not denser than that of high-strength concretes, the movement of moisture can proceed faster, thereby rapidly increasing the humidity, as shown in the uncoated specimens of ordinary strength but with interior waterproofing layer applied. This waterproofing layer blocked the humidity for a short period (approximately three days), thereby preventing the interior humidity from increasing. However, as soon as the moisture delivered from the interior passed through the waterproofing layer, the humidity increased rapidly; thus, the final distribution of humidity is similar to that of the uncoated specimens of ordinary strength.

Furthermore, during the period in which heating was turned off, when the uncoated waterproofed concrete specimens (HSC-N, OPC-N) displayed a faster increase in humidity than the other four specimens, HSC-N, which showed lower humidity than OPC-I, displayed even higher humidity than OPC-I from humidity change zone A, as shown in Figure 7. Based on this result, humidity of concretes with interior waterproofing applied can be controlled within a certain range under low conditions without heat transfer fluids.

According to these test results, uncoated specimens reacted to the changes in the exterior humidity more sensitively than the specimens with interior waterproofing applied; the specimens with exterior waterproofing applied were less sensitive to changes in the exterior humidity than the interior waterproofing applied specimens.

In summary, the preceding test results indicated that high-strength concrete structures are less sensitive to the exterior humidity than ordinary strength concretes; applying waterproofing layers makes concrete structures less sensitive to exterior temperature changes than not applying waterproofing layers to concretes. Moreover, the application of exterior waterproofing more effectively controls the interior humidity than the application of interior waterproofing, so this is considered the most efficient method to prevent condensation.

4.2.2. Test Results of the Specimens in Spring/Autumn Season. The temperature and humidity were measured for eight days, assuming interior heating with heat transfer fluid (light 




(a) Initial humidity change zone B-1

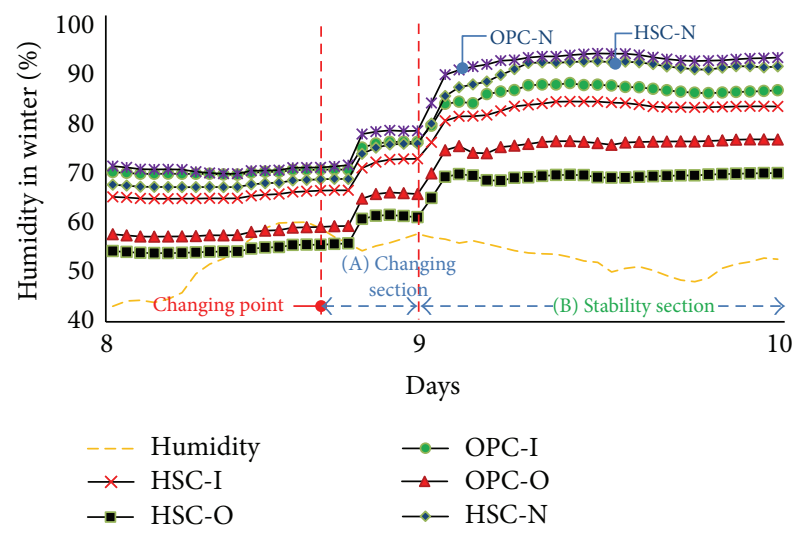

(b) Zone B-1 after heating was turned off

FIGURE 7: Humidity change zone (B-1 and B-2) in the interior of the specimens in winter.

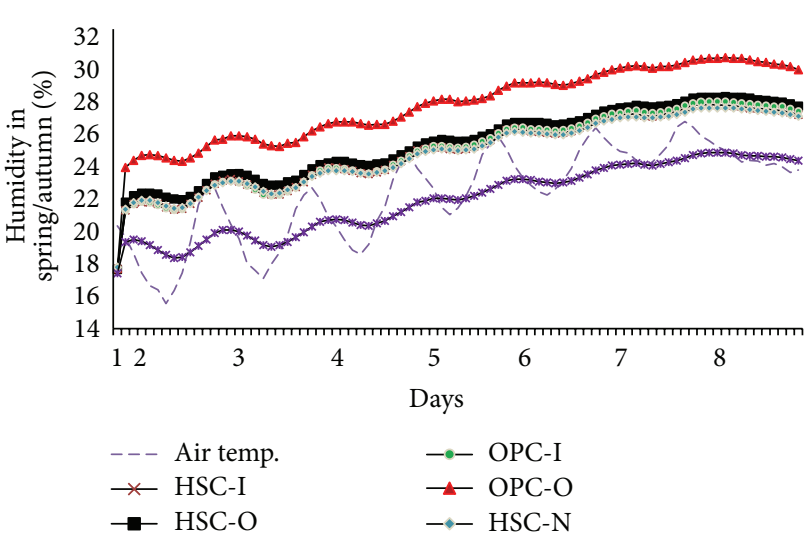

(a)

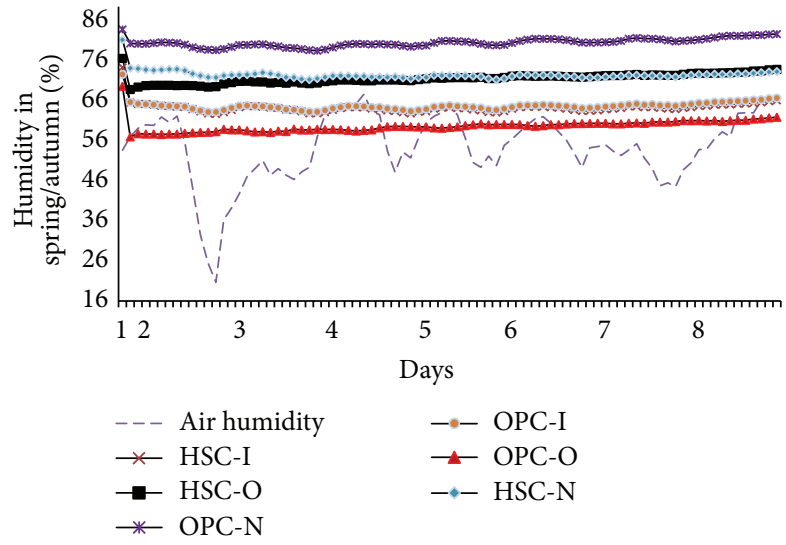

(b)

FIGURE 8: Measurement results of the interior temperature and humidity in spring/autumn.

bulbs), to observe the temperature changes in the interiors of the specimens.

(1) Temperature of the Interior of the Specimens in Spring/ Autumn. The measurement results of the interior temperatures of the specimens in spring/autumn are shown in Figure 8. As shown in this figure, the interior temperatures of the boxes containing six specimens showed a trend similar to the daily changes in exterior temperature, whereas the temperature rank did not change from the start to the end of the test.

The OPC-O specimen maintained the highest temperature, whereas the uncoated ordinary strength specimen exhibited the lowest temperature. The specimens with exterior waterproofing applied maintained a temperature approximately $3^{\circ} \mathrm{C}$ higher, on average, than the uncoated specimens. The specimens with exterior waterproofing applied maintained a temperature approximately $1^{\circ} \mathrm{C}$ higher, on average, than the specimens with interior waterproofing applied. Overall, these results were nearly the same as the winter season conditions, although slight variance was found owing to the exterior temperature conditions.

However, compared to the test results of HSC-O in the winter season, HSC-O in spring/autumn showed a temperature distribution similar to those of the interior waterproofing specimens (HSC-I, OPC-I) or HSC-N. To determine the reason for these results, the condition of the specimens was examined after the test was completed. Damage to the waterproofing layer near the bottom of the specimen was discovered; this occurred during installation of the specimen, thereby causing water leakage inside the specimen. Based on this result, it can be concluded that even if exterior waterproofing is applied, the temperature cannot be controlled if partial leakage occurs or exterior waterproofing is applied only to the outer wall in limited quantities, except for the bottom, to which it is difficult to apply waterproofing material.

(2) Humidity of the Interior of the Specimens in Spring/ Autumn. Figure 8 shows the measurement results of the interior humidity in spring/autumn, in which the specimens that 
maintained the lowest and highest humidity were the same as those in the results of the temperature tests. The humidity difference between the OPC-O and OPC-N was approximately $20 \%$, whereas the difference in humidity between uncoated specimens with and without a waterproofing layer showed a clear distinction. A humidity difference was initially revealed between HSC-N and HSC-O under high-strength conditions, which was due to water leakage in the exterior waterproofing layer; however, few differences were found between the two specimens after five days ("C)" zone). This is because humidity was supplied to the interior owing to the water leakage introduced at the damaged area of the exterior waterproofing layer (urethane-coated waterproof material) that occurred at the bottom of the specimen. Consequently, these specimens exhibited the same humidity condition as the uncoated high-strength specimen.

4.2.3. Test Results of the Specimens in Summer Season. The test was conducted from July 21 to August 3, 2014, for 14 days. To compare the results from heated and unheated conditions, the interior heating in the winter season was assumed while the heat transfer fluid (light bulbs) inside the box was turned off and then turned on after seven days. The test results are shown in Figures 9 and 10.

(1) Temperature of the Interior of the Specimens in Summer. Exterior temperature condition was about $26^{\circ} \mathrm{C} \sim 28^{\circ} \mathrm{C}$ within the minimum duration of 7 days and was about $27^{\circ} \mathrm{C} \sim 34^{\circ} \mathrm{C}$ by the 14th day. The interior temperature of the test specimen reached the temperature of $22^{\circ} \mathrm{C} \sim 24^{\circ} \mathrm{C}$ with relatively small change in the range and reached to about $26^{\circ} \mathrm{C} \sim 36^{\circ} \mathrm{C}$ after heating, a result of relatively large amount of change in the range notwithstanding the test conditions. It was clear that the room temperature was being raised by the bulb used as incandescent lamps that was acting as a medium used to accurately observe the changes occurring within each test piece in the experimental procedure. In particular it was observed that the temperature change due to the winter season temperature testing of high-strength external waterproofing (HSC-O) and standard strength external waterproofing (OPC-O) had little change of approximately $0.5^{\circ} \mathrm{C}$ over the period of 4 days and a large change of temperature of approximately $2.7^{\circ} \mathrm{C}$ over the period of 8 days (heating condition).

As observed in the above via the winter season temperature testing, it can be considered that concrete strength conditions of underground structure external wall specimen with adiabatic conditioning have higher performance than untreated specimen. This phenomenon is due to the fact that high-strength concrete with entrained air has higher performance rate than standard strength concrete that has entrapped air. Furthermore, the difference in performance rate is more clearly shown in higher temperature conditions than lower temperature condition.

(2) Humidity of the Interior of the Specimens in Summer. The results of the experiment indicate that the humidity level of all 6 specimens reached a similar condition with each other

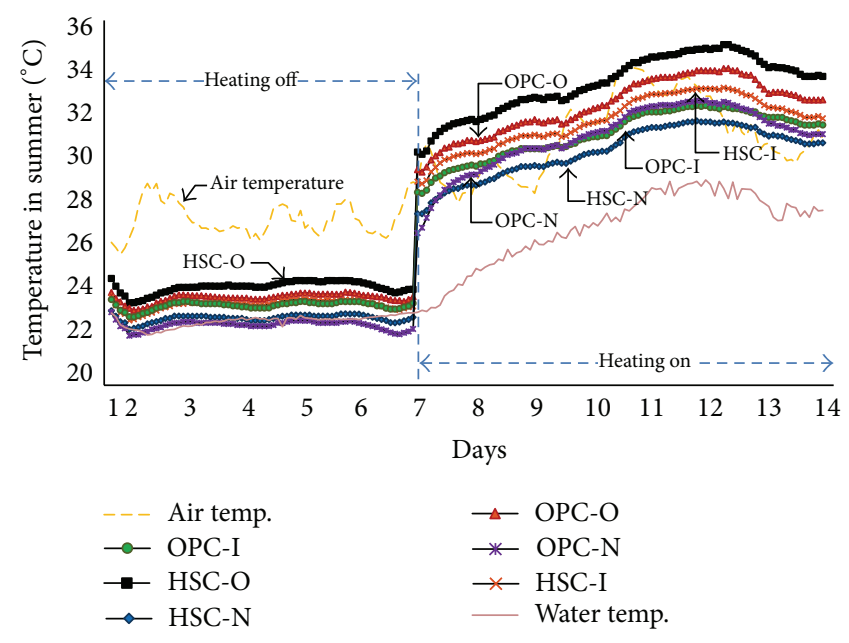

FIGURE 9: Measurement results of the interior temperature in summer.

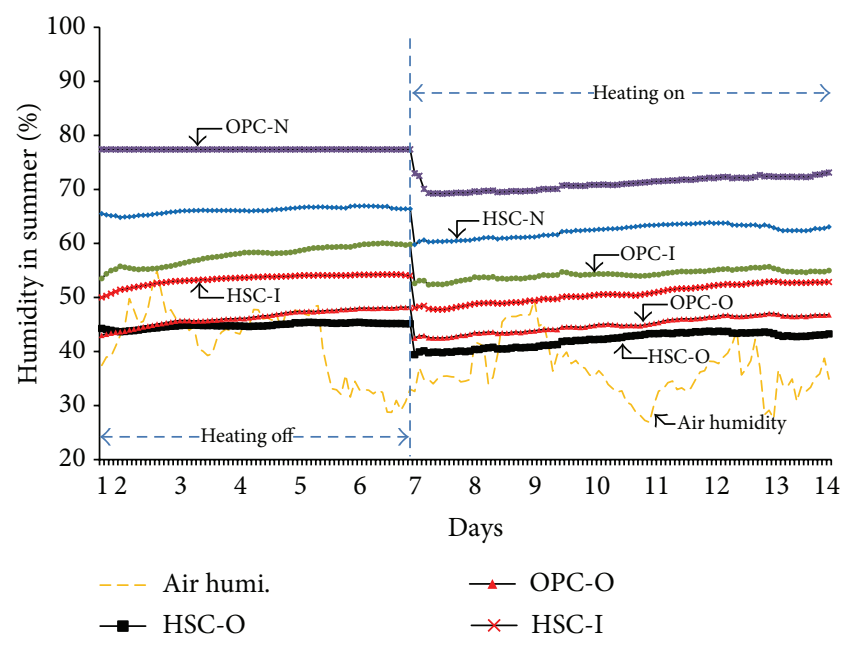

FIGURE 10: Measurement results of the interior humidity in summer.

based on the humidity level change of the external environment. Aside from the high-strength external waterproofing (HSC-O) specimen, the humidity level remained relatively constant from the beginning to the end of the experiment procedure. In the case of standard strength concrete, there was a trend of low increase in humidity 2 days after the beginning of the experiment, whereas the opposite was the case for high-strength concrete where the humidity level fell and retained a consistent humidity level throughout. This is due to the inherent absorbed humidity level of both types of concrete that are discharged in the beginning stages. However, untreated standard concrete had relatively high amount of humidity (approximately 77.4\%) and had a steady flow without measurable amount of humidity level difference prior to heating condition.

After turning on the heating mechanism, humidity level decreased drastically, but respective specimen showed similar rate of humidity level difference. Along with the freezing test, humidity control was made possible by simply turning on the 
heating mechanism, and it was observed that as the concrete material had higher strength, it was proven to have higher level of effectiveness via application on the external wall than on the interior wall.

\section{Conclusion}

The following results were derived in this study through a review of the characteristics of changes in temperature and humidity after the different application of waterproofing layers to underground structures.

(1) The measurement results of temperature and humidity changes in the interior of the specimens in winter indicated that the specimens with the exterior waterproofing applied (HSC-O, OPC-O) maintained a higher temperature of approximately $1.13^{\circ} \mathrm{C}$, on average, than those of specimens with interior waterproofing applied (HSC-I, OPC-I) and uncoated specimens (HSC-N, OPC-N). This finding indicated that when exterior waterproofing was applied, thermal insulation that maintains the interior temperature is steadily secured, which maintains the humidity at an appropriate level and eliminates an environment in which condensation can easily be generated.

(2) It was verified that the uncoated specimen of ordinary strength not only reacted sensitively to changes in the exterior temperature and humidity but also incurred rapid introduction of moisture from the exterior, resulting in significant vulnerability to condensation. In addition, specimens of ordinary strength to which interior waterproofing was applied showed some reduction in humidity effect during the early stage of the test; these specimens displayed the same distribution of humidity as the uncoated specimens of ordinary strength in the humidity stability zone. This revealed that the effect of interior waterproofing was only short term (less than a few days). That is, so long-term humidity control cannot be secured by using interior waterproofing. It is only a matter of time owing to the characteristic of underground structures which is permanently established.

(3) High-strength concrete displayed higher density than ordinary strength concretes, so they influenced changes in temperature and humidity to some extent as a result of denser texture and greater impermeability from the early stage when moisture permeated to the concrete walls. However, it was verified that a more influential factor was the type of waterproofing (exterior waterproofing, interior waterproofing, or no coating) applied to the structures. That is, although high-strength specimens can contribute to the delay in condensation, this cannot be a fundamental solution. More importantly, whether or not the exterior waterproofing layer is applied is the most important factor for the control of the temperature and humidity against an environment displaying easy condensation formation.

(4) Thus, although from the perspective of equipment installation measures may be needed to control the water leakage and condensation inside underground structures (ventilation, heating, and dehumidifying), depending on the location and circumstances, the most fundamental and effective way to control the factors of condensation occurrence (temperature transmission, supply source of humidity, and transmission path) is to apply exterior waterproofing. This is more effective than applying interior waterproofing and highstrength concretes (water-tight concretes).

(5) The exterior high-strength waterproofing specimens in the spring/autumn seasons maintained the same temperature and humidity as the specimens without exterior waterproofing applied owing to damage to the local waterproofing layer (urethane-coated waterproof material). Therefore if partial leakage occurs in the bottom and wall, the temperature and humidity in interior cannot be controlled. Also if the exterior waterproofing is applied to the only outer wall except bottom, it is the same condition.

(6) In the result of summer season temperature testing, there were an approximate increase of $0.37^{\circ} \mathrm{C}$ in temperature and $18.7 \%$ of decrease in humidity for exterior waterproofing compared to interior waterproofing. Consequently, the results remained consistent in both summer season temperature testing and winter season temperature testing where the exterior waterproofing had better temperature and humidity control properties. In the same controlled conditions, the difference was relatively little in the exterior waterproofing setting, high-strength concrete and standard strength concrete both maintained high temperature $\left(0.53^{\circ} \mathrm{C}\right.$ higher $)$ and low humidity level (2.0\% lower). These test results indicate that through exterior waterproofing the concrete material does not absorb humidity and can maintain the entrained air space in the concrete and exhibit its basic insulation capacity.

Through the overview in this result, exterior waterproofing is considered to be highly recommended in order to maintain and secure a fresh environment within the concrete structure. From the designing stage, it is important to consider the application of exterior waterproofing, and, in the case where the concrete structure is displaying high level of water leakage and condensation, application of a proper maintenance management system and reforming the exterior waterproofing layer is determined to be a fundamental solution for completely blocking the entry of moisture.

\section{Conflict of Interests}

The authors declare that there is no conflict of interests regarding the publication of this paper.

\section{Acknowledgment}

This research was supported by Grant 15RERP-B082204-02 from Residential Environment Research Program funded by Ministry of Land, Infrastructure and Transport of Korean government.

\section{References}

[1] P. Mendes, J. G. Lopes, J. de Brito, and J. Feiteira, "Waterproofing of concrete foundations," Journal of Performance of Constructed Facilities, vol. 28, no. 2, pp. 242-249, 2014.

[2] K. Persad, J. O'Connor, and K. Varghese, ForecastngEngineering Manpower, 1995. 
[3] J. Zhang, Y. Gao, and Y. Han, "Interior humidity of concrete under dry-wet cycles," Journal of Materials in Civil Engineering, vol. 24, no. 3, pp. 289-298, 2012.

[4] N. P. Mailvaganam and P. G. Collins, "Workmanship factors influencing quality of installed parking garage waterproofing membranes," Journal of Performance of Constructed Facilities, vol. 18, no. 3, pp. 121-126, 2004.

[5] F.-Q. Zhao, H. Li, S.-J. Liu, and J.-B. Chen, "Preparation and properties of an environment friendly polymer-modified waterproof mortar," Construction and Building Materials, vol. 25, no. 5, pp. 2635-2638, 2011.

[6] D. Derome and G. Desmarais, "Exposure to condensation moisture of sheathing in retrofitted leaky wall assemblies," Journal of Architectural Engineering, vol. 12, no. 2, pp. 72-82, 2006.

[7] Y.-M. Kang, J.-M. Park, J.-H. Choi, O.-K. Kim, and D.-S. Seo, “A study on the issue about the water leak and condensation defect of lawsuit on defect in apartment building," Proceeding of The Architectural Institute of Korea, vol. 31, no. 2, pp. 443-444, 2011.

[8] S.-K. Oh, "A new approach on waterproofing and water-leakage repair technology of concrete structure," Proceedings of the Korean Concrete Institute, no. 5, pp. 101-118, 2002.

[9] L. Cheong and J.-P. Choi, "A study of underground pedestrian movement in residential development," Proceeding of The Architectural Institute of Korea, vol. 31, no. 2, pp. 37-38, 2011.

[10] C. Deckard and P. Duffy, "Rethinking waterproofing for subsurface structures," in Proceedings of the 5th Forensic Engineering Congress, pp. 298-307, Washington, DC, USA, November 2009.

[11] S.-W. Kwon, Y.-S. Seon, S.-M. Choi, Y.-G. Kim, and S.-K. Oh, "A study on the test method to select for waterproofing and repair materials to ensure the leakage safety on the concrete structure-external technology of materials performance test methods," Proceeding of Korea Concrete Institute, vol. 2007, no. 5, pp. 915-918, 2007.

[12] R. A. Johnson, D. S. Leek, and M. P. Cope, Water-Resisting Basement Construction-A Guide, CIRIA Publications, London, UK, 1995.

[13] M.-C. Park, Question and Answer in Design and Construction of Waterproofing, Architectural Technology, 2001.

[14] Y.-S. Moon, S.-C. Lee, G.-J. Gwon, and S.-K. Oh, "A study on the outside waterproof method of ground using wire-mesh and non-hardening viscosity waterproof business waterproofing concrete foundations," Journal of the Korean Institute of Building Construction, vol. 9, no. 1, pp. 213-217, 2009.

[15] S.-M. Choi, S.-K. Oh, and C.-H. Seo, "Construction of an evaluation system for selecting an appropriate waterproofing method for the roof of a building," Canadian Journal of Civil Engineering, vol. 39, no. 12, pp. 1264-1273, 2012.

[16] S.-M. Chang, S.-M. Choi, and S.-K. Oh, "Analysis of the temperature-humidity changing characteristics by the applying type of the waterproofing methods in the basement parking lot in the winter," Journal of Architectural Institute of Korea Region Alliance, vol. 16, no. 1, pp. 217-223, 2014.

[17] Y.-G. Kim, S.-K. Oh, and B.-K. Park, "A study on physical properties of cement-polymer modified waterproof membrane coatings," Journal of the Architectural Institute of Korea Structure \& Construction, vol. 19, no. 9, pp. 79-86, 2003.

[18] Korean Standards Association, "Waterproofing membrane coating for construction," KS F 3211, KSA, 2008.

[19] Korean Standards Association, "Cement-polymer modified waterproof coatings,” KS F 4919, KSA, 2007. 

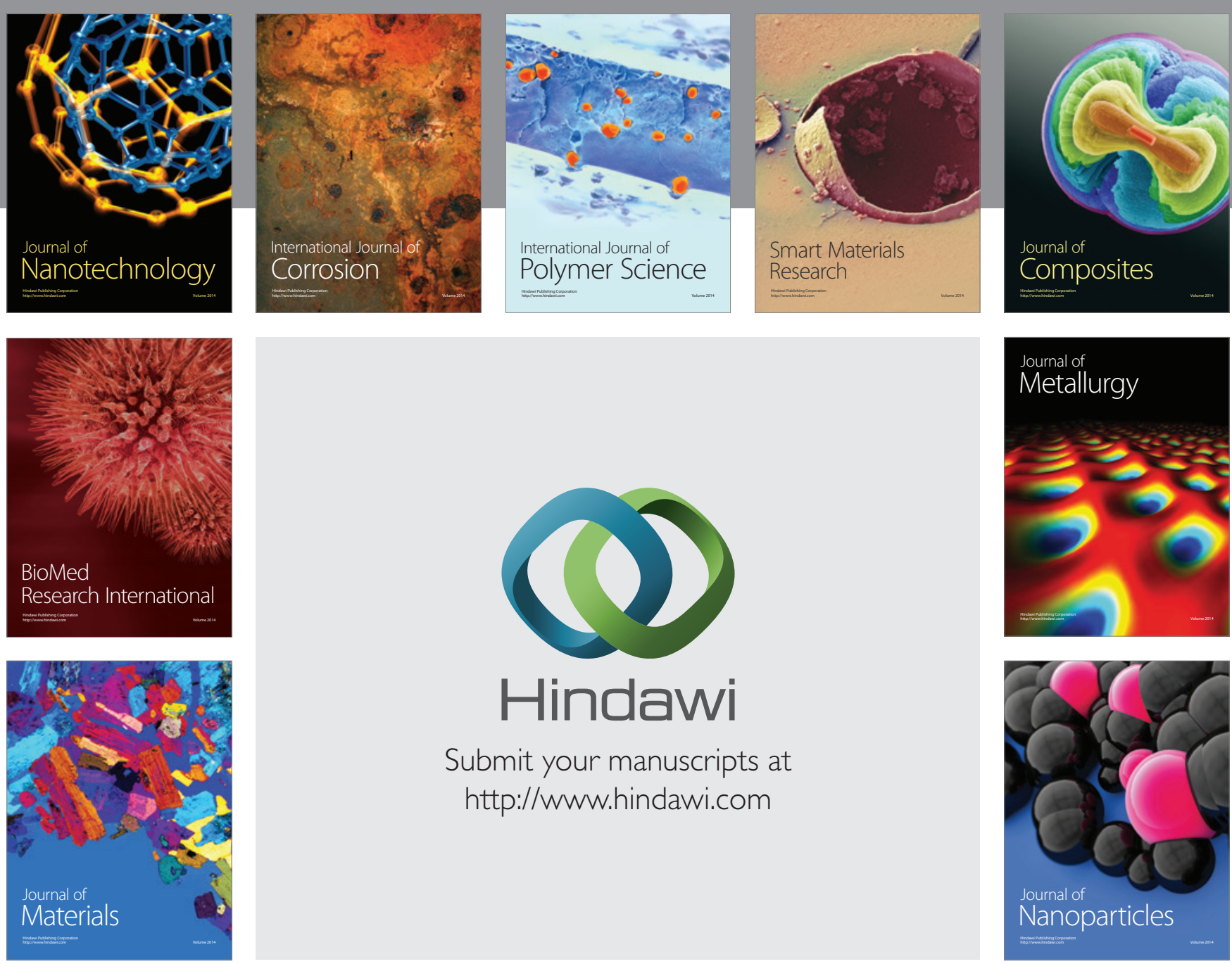

Submit your manuscripts at http://www.hindawi.com
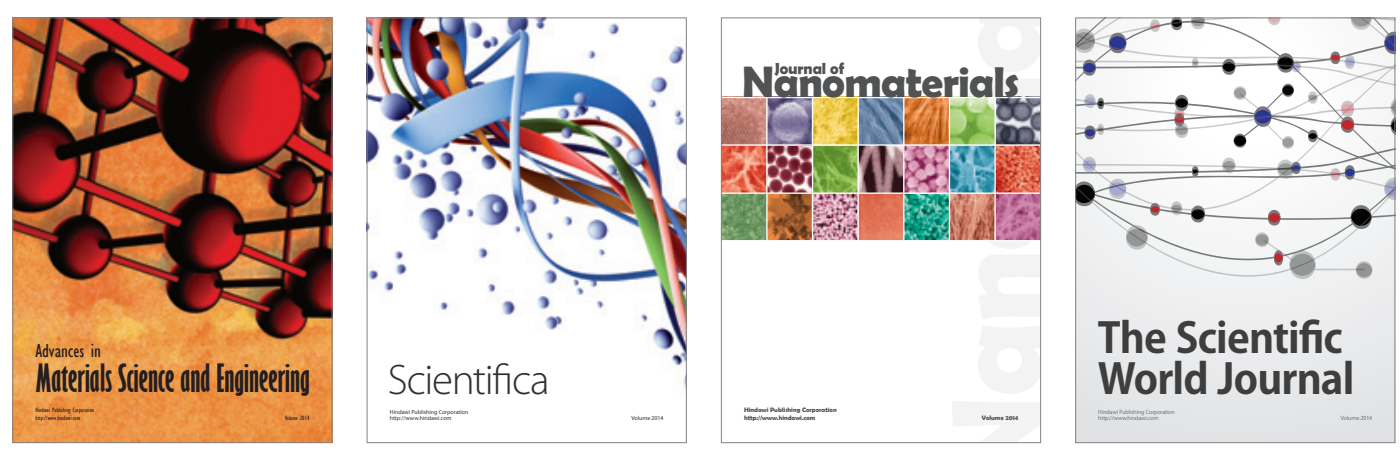

\section{The Scientific World Journal}
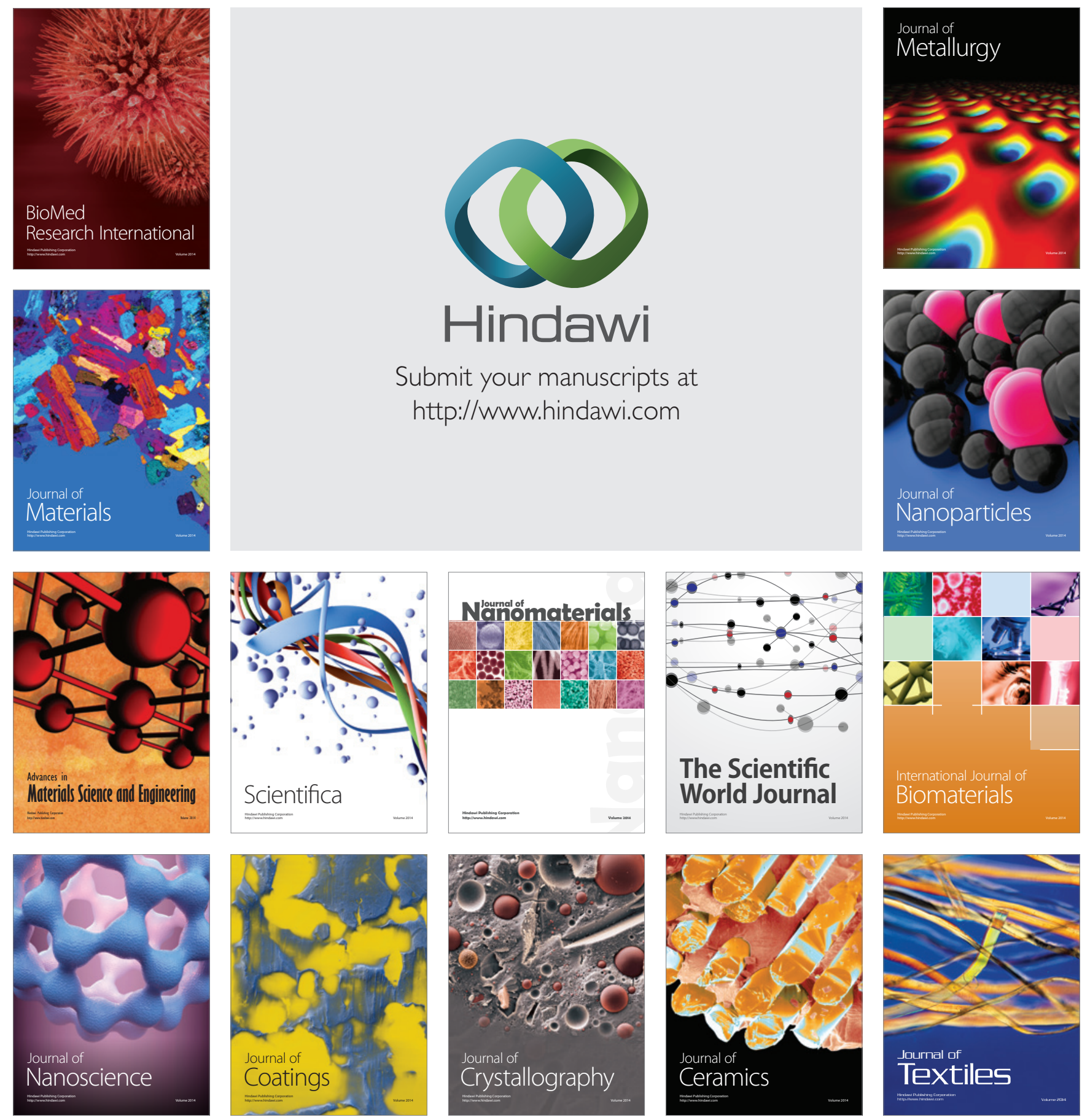